\title{
PENGELOLAAN AIR LIMBAH RUMAH POTONG HEWAN DI RPH X, KOTA BOGOR, PROVINSI JAWA BARAT \\ (Wastewater Management of Slaughterhouse in Slaughterhouse X, Bogor City, West Java Province)
}

\author{
Irma Lubis*, Tri Edhi Budhi Soesilo dan Roekmijati W. Soemantojo \\ Sekolah Ilmu Lingkungan, Universitas Indonesia, Jl. Salemba Raya No. 4 - Jakarta Pusat. \\ *Penulis korespondensi. Tel: 08561300203. Email: lubisirma@gmail.com.
}

Diterima: 10 Mei 2017

Disetujui: 10 September 2017

\begin{abstract}
Abstrak
Air limbah Rumah Potong Hewan (RPH) yang tidak dikelola dengan baik dapat menimbulkan masalah lingkungan dan gangguan pada masyarakat yang bertempat tinggal di sekitar RPH. Sejak RPH X beroperasi pada tahun 2009, pengelolaan air limbah RPH X masih belum berjalan optimal. Hal ini dikarenakan air limbah RPH X masih dilihat sebagai materi yang tidak berguna dan dibuang. Saat ini, praktik pengelolaan air limbah RPH X dilakukan dengan menggabungkan semua air limbah kemudian air limbah tersebut diolah dengan Instalasi Pengolahan Air Limbah (IPAL). Riset ini mencoba menganalisis praktik pemotongan sapi, fasilitas RPH, pengelolaan air limbah RPH, kualitas air limbah RPH, dan dampak limbah RPH pada masyarakat. Riset ini menggunakan pendekatan metode kuantitatif dan kualitatif, melalui observasi, wawancara, kuesioner, dan uji laboratorium. Hasil riset menunjukkan bahwa praktik pemotongan sapi di RPH X termasuk kategori baik, fasilitas RPH X termasuk kategori kurang sesuai dengan persyaratan, pengelolaan air limbah RPH X belum berjalan optimal, kualitas air outlet IPAL telah memenuhi baku mutu, dan dampak limbah RPH X pada masyarakat berupa gangguan bau yang dirasakan oleh $100 \%$ responden dan gangguan kesehatan berupa mual yang dirasakan oleh $41 \%$ responden. Alternatif peningkatan dalam pengelolaan air limbah RPH yang dapat dilakukan adalah minimisasi air limbah melalui segregasi dan pemanfaatan air limbah RPH.
\end{abstract}

Kata kunci: Rumah Potong Hewan, pengelolaan air limbah RPH, kualitas air limbah RPH, dampak limbah RPH, minimisasi

\begin{abstract}
Wastewater of slaughterhouse is not managed optimally can cause environmental problems and disruption to communities living around the slaughterhouse. Since slaughterhouse X operates in 2009, wastewater management of the slaughterhouse $X$ is not managed optimally. This is because the wastewater of the slaughterhouse $X$ is seen as useless and discarded material. Currently, the wastewater management of the slaughterhouse $X$ is carried out by mixing all of the wastewater and then the wastewater is treated by Wastewater Treatment Plant (WWTP). This study analyzes practice of cattle slaughtering, slaughterhouse facilities, wastewater management, wastewater quality, impact of slaughterhouse waste. This study exercises quantitative and qualitative methods, through observations, interviews, questionnaires, and laboratory test. The results showed that the practice of cattle slaughtering was categorized into good, the slaughterhouse X facilities were categorized into less suitable, the wastewater management of slaughterhouse $X$ is still not managed optimally, the wastewater quality of WWTP outlet is comply with water quality standards, and the impact of slaughterhouse waste to the communities living around the slaughterhouse is odor disruption felt by $100 \%$ of respondents and health issue are nauseous felt by $41 \%$ of respondents. An alternative to improving wastewater management of slaughterhouse is minimization through segregation and utilization of slaughterhouse wastewater.
\end{abstract}

Keywords: slaughterhouse; wastewater management; wastewater quality; impact of slaughterhouse waste; minimization.

\section{PENDAHULUAN}

Jumlah pemotongan sapi tercatat di Indonesia cenderung meningkat setiap tahunnya. Berdasarkan data statistik peternakan dan kesehatan hewan tahun 2016, jumlah pemotongan sapi tercatat di Indonesia pada tahun 2015 sekitar 2,1 juta sapi atau meningkat sekitar 2,3\% dari tahun 2014. Pada tahun 2015, jumlah pemotongan sapi tercatat paling banyak berada di Jawa Timur sebesar 358.356 sapi, diikuti oleh Jawa Barat sebesar 274.731 sapi atau persentase masing-masing sekitar 16,5 dan $12,6 \%$ dari total jumlah pemotongan sapi tercatat di Indonesia. Jumlah pemotongan sapi tercatat di Jawa Barat cenderung meningkat setiap tahunnya. Berdasarkan data statistik peternakan dan kesehatan hewan tahun 2016, jumlah pemotongan sapi tercatat di Jawa Barat pada tahun 2015 sebesar 274.731 sapi atau meningkat sekitar 17\% dari tahun 2014. Pada tahun 2015 , jumlah pemotongan sapi tercatat masih mendominasi pemotongan ternak tercatat di Jawa Barat. Persentase jumlah pemotongan sapi tercatat 
pada tahun 2015 sekitar 75,1\%; diikuti pemotongan domba $16,9 \%$; pemotongan babi $6,1 \%$; pemotongan kambing 1,4\%; dan pemotongan kerbau 0,5\% (BPS Provinsi Jawa Barat, 2015).

Rumah Potong Hewan (RPH) adalah suatu bangunan atau komplek bangunan dengan desain dan syarat tertentu yang digunakan sebagai tempat memotong hewan bagi konsumsi masyarakat umum. Lokasi RPH harus memenuhi persyaratan yaitu tidak menimbulkan gangguan dan pencemaran lingkungan dan mempunyai akses air bersih yang cukup untuk pelaksanaan pemotongan hewan dan kegiatan pembersihan serta disinfeksi. Setiap kabupaten/kota harus mempunyai RPH yang memenuhi persyaratan teknis yang ditetapkan oleh menteri pertanian. Untuk menyediakan daging yang Aman, Sehat, Utuh, dan Halal (ASUH), RPH harus memenuhi persyaratan teknis yang meliputi fisik (bangunan dan peralatan), sumber daya manusia, dan prosedur teknis pelaksanaannya. Berdasarkan hasil evaluasi dan pemantauan Direktorat Kesehatan Masyarakat Veteriner dan Pascapanen Kementerian Pertanian, sebagian besar kondisi RPH di Indonesia cukup memprihatinkan dan tidak memenuhi persyaratan teknis sehingga perlu dilakukan penataan RPH melalui upaya relokasi, renovasi, atau rehabilitasi. Senada dengan riset sebelumnya yang dilakukan oleh Tawaf et al. (2013) yang menemukan bahwa dari 20 RPH di Jawa dan Nusa Tenggara yang diamati kondisi fisiknya, hanya $20 \%$ yang termasuk kategori layak secara teknis sementara sisanya masih di bawah standar kelayakan teknis.

Secara ringkas, kegiatan pemotongan hewan di $\mathrm{RPH}$ terdiri atas penerimaan dan penampungan, pemeriksaan ante-mortem, persiapan penyembelihan, penyembelihan, pengulitan, pengeluaran jeroan, pemeriksaan post-mortem, pembelahan karkas, pelayuan karkas, dan pengangkutan karkas. Praktik pemotongan hewan di RPH dapat dinilai berdasarkan Good Slaughtering Practices (GSP). Menurut CAC (2004), GSP adalah seluruh praktik di RPH yang berkaitan dengan kondisi dan tindakan yang dibutuhkan untuk menjamin keamanan dan kelayakan pangan pada seluruh tahapan dalam rantai pangan. Selain itu, untuk mendukung praktik pemotongan hewan yang berdasarkan GSP maka diperlukan fasilitas RPH yang memadai. Fasilitas RPH dapat dievaluasi dengan cara membandingkan dengan peraturan yang berlaku.

Kegiatan pemotongan hewan di RPH menghasilkan produk samping berupa air limbah RPH. Air limbah RPH adalah limbah organik biodegradable yang terdiri atas darah, sisa-sisa pencernaan, urin, dan pencemar lainnya yang dihasilkan dari proses pencucian (Budiyono et al.,
2011). Air limbah RPH sebagian besar dihasilkan dari air pembersihan ruang pemotongan, air pencucian saluran pencernaan, dan air pembersihan kandang hewan dengan beban pencemaran terbesar berasal dari darah (Padmono, 2005). Akan dan Mohmoud (2010) melaporkan bahwa parameter fisika, kimia, dan biologi air limbah RPH melebihi peraturan yang berlaku sehingga berbahaya bagi lingkungan, kehidupan akuatik, dan kesehatan manusia. Air limbah RPH jika mencemari perairan dapat menjadi media pertumbuhan dan perkembangan mikroba sehingga menyebabkan terjadinya pemanfaatan oksigen terlarut di dalam air. Pemanfaatan oksigen terlarut yang berlebihan dapat mengakibatkan terjadinya degradasi kualitas air. Selain itu, aktivitas mikroba dalam proses pembusukan limbah organik di dalam air mengakibatkan terjadinya peningkatan konsentrasi Biological Oxygen Demand (BOD), Chemical Oxygen Demand (COD), amonia $\left(\mathrm{NH}_{3}\right)$, hidrogen sulfida $\left(\mathrm{H}_{2} \mathrm{~S}\right)$, perubahan $\mathrm{pH}$, dan menimbulkan bau busuk seperti bau urea dan belerang (Widya et al., 2008). Konsentrasi pencemar dalam air limbah RPH ini harus diturunkan hingga memenuhi baku mutunya agar tidak mencemari lingkungan. Baku mutu air limbah bagi kegiatan RPH diatur dalam Peraturan Menteri Lingkungan Hidup Republik Indonesia No. 5 tahun 2014 tentang Baku Mutu Air Limbah (Lampiran XLV).

Limbah RPH yang tidak dikelola dengan baik berpotensi untuk mencemari lingkungan. Menurut Akinro et al. (2009), produksi daging di RPH dapat menimbulkan masalah lingkungan apabila limbahnya tidak diolah dengan baik. Selain itu, limbah RPH yang tidak dikelola dengan baik dapat berdampak pada masyarakat yang bertempat tinggal di sekitar RPH. Menurut Singh et al. (2014), kegiatan RPH mempengaruhi kualitas air, tanah, dan udara di sekitarnya. Dampak ini dapat dirasakan oleh masyarakat yang bertempat tinggal dekat dengan RPH. Riset sebelumnya yang dilakukan oleh Bello (2009) menunjukkan bahwa 98\% masyarakat yang bertempat tinggal dekat dengan RPH merasa terganggu dengan keberadaan RPH. Pembuangan limbah RPH di area terbuka dan badan air dapat mencemari lingkungan dan menimbulkan penyakit yang dampaknya dapat dirasakan oleh masyarakat yang bertempat tinggal di sekitar RPH. Berdasarkan Peraturan Menteri Lingkungan Hidup Republik Indonesia No. 2 tahun 2006, setiap penanggungjawab usaha dan/atau kegiatan RPH wajib melakukan pengolahan air limbah sehingga mutu air limbah yang dibuang atau dilepas ke lingkungan tidak melampaui baku mutu air limbah RPH. 
Rumah Potong Hewan (RPH) X adalah salah satu RPH terbesar di Jawa Barat. RPH X adalah RPH milik pemerintah yang berada di bawah pembinaan dan pengawasan Dinas Pertanian Kota Bogor. RPH X menyediakan jasa pemotongan sapi, kerbau, kambing, domba, dan unggas. Pada tahun 2010, jumlah hewan yang dipotong di RPH X yaitu sebesar 32.066 hewan yang terdiri atas 11.816 sapi dan 20.250 ayam (Iskandar, 2014). Jumlah hewan yang dipotong tersebut telah mencapai $157,5 \%$ yang melebihi sasaran pencapaian Rencana Pembangunan Jangka Menengah Daerah (RPJMD) tahun 2010 yaitu sebesar 20.360 hewan (Iskandar, 2014). Semakin banyak jumlah hewan yang dipotong di RPH X maka semakin besar volume air limbah RPH X yang dihasilkan. Kondisi ini berpotensi untuk mencemari lingkungan apabila air limbah RPH X tidak dikelola secara optimal. Belum adanya upaya untuk mengkaji pengelolaan air limbah di RPH X menjadi alasan peneliti untuk menganalisis praktik pemotongan sapi di RPH X, fasilitas RPH X, pengelolaan dan kualitas air limbah RPH X, dan dampak limbah RPH X pada masyarakat yang bertempat tinggal di sekitar RPH $\mathrm{X}$.

Sejak RPH X beroperasi pada tahun 2009, pengelolaan air limbah RPH X masih belum berjalan optimal. Hal ini dikarenakan air limbah RPH X masih dilihat sebagai materi yang tidak berguna dan dibuang. Saat ini, praktik pengelolaan air limbah RPH $\mathrm{X}$ dilakukan dengan menggabungkan semua air limbah kemudian air limbah tersebut diolah dengan Instalasi Pengolahan Air Limbah (IPAL). Berdasarkan riset sebelumnya, praktik pemotongan sapi yang sesuai dengan prinsip Good Slaughtering Practices (GSP), fasilitas RPH yang memadai, dan pengelolaan air limbah RPH yang optimal seharusnya dapat menjaga kualitas air limbah RPH di bawah baku mutunya dan mengurangi dampak limbah RPH pada masyarakat yang bertempat tinggal di sekitar $\mathrm{RPH}$. Berdasarkan pemaparan tersebut, maka tujuan pada riset ini adalah menganalisis praktik pemotongan sapi di RPH X sesuai dengan prinsip GSP, menganalisis fasilitas RPH X, mengenalisis pengelolaan air limbah RPH $\mathrm{X}$, menganalisis kualitas air limbah RPH X, dan menganalisis dampak limbah RPH X pada masyarakat yang bertempat tinggal di sekitar RPH X.

\section{METODE PENELITIAN}

\section{Waktu dan Lokasi}

Riset ini dilaksanakan selama 9 bulan yaitu mulai bulan April 2017 sampai dengan Desember 2017. Tempat pelaksanaan riset ini adalah RPH X. RPH X berlokasi di Kelurahan Bubulak,
Kecamatan Bogor Barat, Kota Bogor, Provinsi Jawa Barat. Tempat riset ini dipilih karena RPH X adalah salah satu RPH terbesar di Jawa Barat, sehingga diperlukan pengelolaan air limbah RPH yang optimal untuk mengurangi terjadinya pencemaran lingkungan. RPH $\mathrm{X}$ memiliki luas $50.000 \mathrm{~m}^{2}$ dengan titik koordinat $106^{\circ} 45^{\prime}, 28,6^{\prime \prime}$ $106^{\circ} 45^{\prime} 33,4^{\prime \prime}$ Bujur Timur dan $06^{\circ} 34^{\prime} 05,5^{\prime \prime}-06^{\circ}$ 33' 56,2" Lintang Selatan.

\section{Prosedur}

Riset ini dimulai dengan studi literatur dan observasi awal terkait pengelolaan air limbah di RPH X. Riset dilanjutkan dengan observasi dan wawancara mendalam terkait praktik pemotongan sapi, fasilitas RPH, dan pengolahan air limbah di RPH X. Riset dilanjutkan dengan pengambilan sampel air limbah RPH X untuk diuji kualitas air limbahnya di laboratorium. Riset dilanjutkan dengan penyebaran kuesioner kepada masyarakat yang bertempat tinggal di sekitar RPH X, wawancara dengan Kepala RW dan perwakilan masyarakat. Selanjutnya dilakukan pengolahan dan analisis data.

Secara umum, pendekatan yang digunakan pada riset ini adalah pendekatan kuantitatif. Pendekatan ini dipilih karena data riset berupa nilai dari variabel yang terukur. Metode yang digunakan pada riset ini adalah gabungan antara metode kuantitatif dan kualitatif. Metode kuantitatif digunakan untuk mendapatkan data terkait praktik pemotongan sapi, fasilitas RPH, kualitas air limbah RPH, dan dampak limbah RPH pada masyarakat yang bertempat tinggal di sekitar RPH. Metode kualitatif digunakan untuk mendapatkan data terkait pengelolaan air limbah RPH.

\section{Populasi dan Sampel}

Populasi pada riset ini terdiri atas empat populasi yaitu pengelola RPH, RPH, air limbah $\mathrm{RPH}$, dan masyarakat. Populasi pengelola RPH adalah semua pegawai atau pekerja yang bertanggung jawab terhadap kegiatan operasional di RPH X. Penentuan sampel dilakukan dengan teknik purposive sampling yaitu pegawai atau pekerja yang dapat memberikan informasi terkait tujuan pertama yaitu menganalisis praktik pemotongan sapi di RPH X Populasi RPH adalah seluruh kondisi fisik fasilitas di RPH X. Penentuan sampel dilakukan dengan teknik purposive sampling yaitu kondisi fisik fasilitas di RPH X yang dapat digunakan untuk menjawab tujuan kedua yaitu mengevaluasi fasilitas RPH X.

Populasi air limbah RPH adalah semua air limbah yang dihasilkan dari kegiatan pemotongan hewan di RPH X. Penentuan sampel dilakukan dengan teknik purposive sampling yaitu air limbah 
RPH X sebelum diolah dengan IPAL (inlet) dan air limbah RPH X setelah diolah dengan IPAL (outlet). Populasi masyarakat adalah semua Kepala Keluarga (KK) yang bertempat tinggal di RW 2 Kelurahan Bubulak. Pada Tahun 2017, jumlah KK di RW 2 Kelurahan Bubulak adalah 260 KK. Penentuan jumlah sampel dilakukan berdasarkan pendapat umum (rule of thumb) yang menyatakan bahwa sampel berjumlah 30-500 dapat efektif, bergantung pada desain penarikan sampel tersebut (Sudaryono, 2014).

\section{Variabel Operasional}

Variabel pada riset ini terdiri atas praktik pemotongan sapi, fasilitas RPH, kualitas air limbah RPH, dan dampak limbah RPH pada masyarakat. Definisi dari masing-masing variabel dapat dilihat pada Tabel 1.

\section{Uji Analisis Variabel}

Metode analisis pada riset ini dilakukan berdasarkan data primer dan data sekunder yang diperoleh. Uji analisis praktik pemotongan sapi dilakukan dengan observasi dan wawancara kemudian hasilnya digunakan untuk menilai matriks evaluasi praktik pemotongan sapi berdasarkan prinsip GSP. Uji analisis fasilitas RPH dilakukan dengan observasi dan wawancara kemudian hasilnya digunakan untuk menilai matriks fasilitas RPH. Uji analisis pengelolaan air limbah RPH dilakukan dengan observasi dan wawancara kemudian hasilnya digunakan untuk membuat diagram alir pengelolaan air limbah RPH. Uji analisis kualitas air limbah RPH dilakukan dengan pengukuran kualitas air limbah RPH X pada outlet IPAL dianalisis dengan metode Storet.

\section{HASIL DAN PEMBAHASAN}

\section{Praktik Pemotongan Sapi di RPH X}

Pada tahun 2017, jumlah sapi yang dipotong di RPH X mencapai rata-rata $40 \mathrm{sapi} /$ hari. Rata-rata jumlah sapi yang dipotong per hari ini masih di bawah kapasitas pemotongan sapi di RPH X yaitu 100 sapi/hari. Oleh karena itu, berdasarkan jumlah pemotongan hewan maka RPH X termasuk RPH Kategori III yaitu jumlah pemotongan sapi atau kerbau 50 hewan/hari. Namun pada Hari Raya Idul Adha, jumlah sapi yang dipotong di RPH X melebihi kapasitas pemotongan sapi yaitu mencapai 100 sapi/hari selama tiga hari berturut-turut. Kondisi ini membutuhkan pengelolaan limbah RPH

Tabel 1. Matrix variabel penelitian.

\begin{tabular}{|c|c|c|}
\hline No. & Variabel & Definisi Operasional \\
\hline 1 & Praktik pemotongan sapi & $\begin{array}{l}\text { Pelaksanaan kegiatan penyembelihan sapi dari awal hingga } \\
\text { akhir yang terdiri atas penerimaan dan penampungan, } \\
\text { pemeriksaan ante-mortem, persiapan penyembelihan, } \\
\text { penyembelihan, pengulitan, pengeluaran jeroan, pemeriksaan } \\
\text { post-mortem, pembelahan karkas, pelayuan karkas, dan } \\
\text { pengangkutan karkas. }\end{array}$ \\
\hline 2 & Fasilitas RPH & $\begin{array}{l}\text { Kondisi fisik RPH yang terdiri atas lokasi, sarana/prasarana } \\
\text { pendukung, bangunan utama, area penurunan hewan, kandang } \\
\text { penampung dan istirahat hewan, kandang penampung } \\
\text { ruminansia betina produktif, kandang isolasi, area pemuatan } \\
\text { karkas dan/atau daging, kantor administrasi dan kantor dokter } \\
\text { hewan, kantin dan mushola, ruang istirahat karyawan dan } \\
\text { tempat penyimpanan barang pribadi/ruang ganti pakaian, } \\
\text { kamar mandi dan WC, fasilitas pemusnahan bangkai atau } \\
\text { insinerator, sarana penanganan limbah, rumah jaga, peralatan, } \\
\text { higiene dan sanitasi. }\end{array}$ \\
\hline 3 & $\begin{array}{l}\text { Pengelolaan air limbah } \\
\text { RPH }\end{array}$ & $\begin{array}{l}\text { Pelaksanaan tata kelola air limbah yang dihasilkan dari } \\
\text { kegiatan pemotongan sapi di RPH. }\end{array}$ \\
\hline 4 & Kualitas air limbah RPH & $\begin{array}{l}\text { Mutu produk samping berwujud cair yang dihasilkan dari } \\
\text { kegiatan pemotongan sapi di RPH yang terdiri atas parameter } \\
\text { fisika (TSS) dan parameter kimia (BOD, COD, minyak dan } \\
\text { lemak, amonia, pH) sesuai dengan Peraturan Menteri } \\
\text { Lingkungan Hidup Republik Indonesia No. } 5 \text { tahun } 2014 \\
\text { tentang Baku Mutu Air Limbah (Lampiran XLV) serta } \\
\text { parameter mikrobiologi (bakteri fecal). }\end{array}$ \\
\hline 5 & $\begin{array}{l}\text { Dampak limbah } \mathrm{RPH} \\
\text { pada masyarakat }\end{array}$ & $\begin{array}{l}\text { Gangguan bau dan kesehatan yang dirasakan oleh masyarakat } \\
\text { yang bertempat tinggal di sekitar } \mathrm{RPH} \text {. }\end{array}$ \\
\hline
\end{tabular}




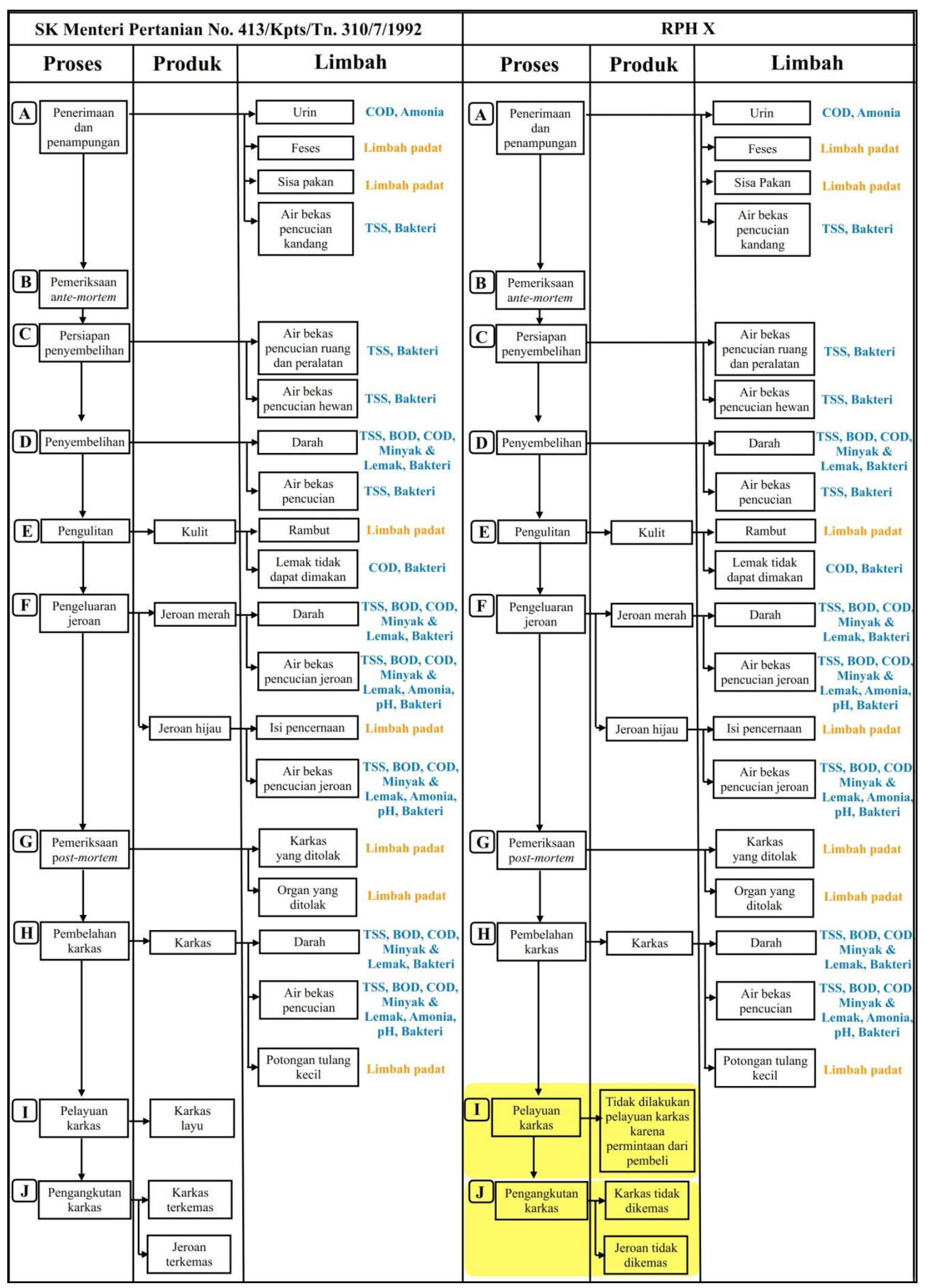

Gambar 1. Diagram Alir Pemotongan Sapi di RPH X (Sumber: Kementerian Pertanian, hasil olah data primer, 2017).

$\mathrm{X}$ yang optimal untuk mencegah terjadinya pencemaran lingkungan. Mengacu pada prosedur operasional standar pemotongan hewan yang ditetapkan oleh Menteri Pertanian, proses pemotongan hewan terdiri atas penerimaan dan penampungan, pemeriksaan ante-mortem, persiapan penyembelihan, penyembelihan, pengulitan, pengeluaran jeroan, pemeriksaan post-mortem, pembelahan karkas, pelayuan karkas, dan pengangkutan karkas. Diagram alir pemotongan sapi di RPH X dapat dilihat pada Gambar 1.

Berdasarkan Gambar 1, proses pemotongan hewan di RPH X terdiri atas penerimaan dan penampungan, pemeriksaan ante-mortem, persiapan 
penyembelihan, penyembelihan, pengulitan, pengeluaran jeroan, pemeriksaan post-mortem, pembelahan karkas, dan pengangkutan karkas. RPH $\mathrm{X}$ tidak melakukan pelayuan karkas dikarenakan permintaan dari pembeli. Oleh karena itu, berdasarkan kelengkapan fasilitas proses pelayuan karkas maka RPH X termasuk RPH Kategori I yaitu RPH tanpa fasilitas pelayuan karkas untuk menghasilkan karkas hangat. Hasil observasi juga menunjukkan bahwa RPH X tidak melakukan pengemasan karkas dan jeroan. Kondisi ini dapat menyebabkan karkas/daging terkontaminasi dari luar pada saat pengangkutan karkas. Hasil valuasi terhadap pemotongan sapi menggunakan matriks yang mengacu pada Surat Keputusan Menteri Pertanian No. 413/Kpts/TN.310/7/1992 tentang Pemotongan Hewan Potong dan Penanganan Daging serta Ikutannya dan Peraturan Pemerintah Republik Indonesia No. 95 tahun 2012 tentang Kesehatan Masyarakat Veteriner dapat dilihat pada Tabel 2.

Berdasarkan Tabel 2, total nilai evaluasi praktik pemotongan sapi di RPH X adalah 75 yang

berarti bahwa praktik pemotongan sapi di RPH X termasuk kategori baik.

\section{Fasilitas RPH X}

Pembobotan pada parameter matriks fasilitas RPH didasarkan pada fasilitas yang mendukung pemotongan hewan. Pembobotan tertinggi yaitu parameter bangunan utama dengan bobot 18 . Hal ini dikarenakan proses pemotongan hewan sebagian besar dilakukan di bangunan utama. Bangunan utama yang sesuai dengan persyaratan dapat mendukung proses pemotongan hewan yang sesuai dengan prosedur. Selain itu, parameter peralatan juga mendukung terlaksananya proses pemotongan hewan yang sesuai dengan prosedur. Dasar pembobotan lainnya adalah pengelolaan lingkungan. Parameter higiene dan sanitasi yang sesuai dengan persyaratan dapat mengurangi pencemaran lingkungan yang dapat ditimbulkan. Matriks ini mengacu pada Peraturan Menteri Pertanian No. 13/Permentan/OT.140/2010 tentang Persyaratan Rumah Potong Hewan Ruminansia dan Unit Penanganan Daging (Meat Cutting Plant). Nilai evaluasi fasilitas RPH X dapat dilihat pada Tabel 3.

Tabel 2. Nilai evaluasi praktik pemotongan sapi di RPH X.

\begin{tabular}{clrrl}
\hline No. & \multicolumn{1}{c}{ Parameter } & Bobot & Nilai & \multicolumn{1}{c}{ Kesesuaian dengan prosedur } \\
\hline A & Penerimaan dan penampungan & 7,5 & 5,75 & Kurang sesuai \\
B & Pemeriksaan ante-mortem & 12,5 & 12,5 & Sesuai \\
C & Persiapan penyembelihan & 7,5 & 5,0 & Kurang sesuai \\
D & Penyembelihan & 20,0 & 13,0 & Kurang sesuai \\
E & Pengulitan & 7,5 & 5,0 & Kurang sesuai \\
F & Pengeluaran jeroan & 12,5 & 12,5 & Sesuai \\
G & Pemeriksaan post-mortem & 12,5 & 12,5 & Sesuai \\
H & Pembelahan karkas & 7,5 & 7,5 & Sesuai \\
I & Pelayuan karkas & 5,0 & 1,25 & Kurang sesuai \\
J & Pengangkutan karkas & 7,5 & 0 & Tidak Sesuai \\
\hline Total nilai & 100 & 75 & \\
\hline
\end{tabular}

Tabel 3. Nilai evaluasi fasilitas RPH X.

\begin{tabular}{llrr}
\hline No. & \multicolumn{1}{c}{ Parameter } & Bobot & Nilai kesesuaian \\
\hline A & Lokasi & 8 & 22,5 \\
B & Sarana/prasarana pendukung & 6 & 18 \\
C & Bangunan utama & 18 & 37 \\
D & Area penurunan hewan & 4 & 9 \\
E & Kandang penampung dan istirahat hewan & 7 & 0 \\
F & Kandang penampung ruminansia betina produktif & 2 & 11 \\
G & Kandang isolasi & 4 & 5 \\
H & Area pemuatan karkas dan/atau daging & 4 & 4,5 \\
I & Kantor administrasi dan kantor dokter hewan & 2 & 2,25 \\
J & Kantin dan mushola & 1 & 0 \\
K & Ruang istirahat karyawan dan tempat penyimpanan barang & 2 & 6 \\
L & pribadi/ruang ganti pakaian & 2 & 5 \\
M & Famar mandi dan WC & 3 & 8 \\
N & Sarana penanganan limbah & 3 & 27 \\
O & Rumah jaga & 4 & 21 \\
P & Peralatan & 6 & 199 \\
Q & Higiene dan sanitasi & 1 & 14 \\
\hline Total & $\quad$ & 14 & 100 \\
\hline
\end{tabular}


Berdasarkan Tabel 3, total Nilai Kesesuaian (NK) pada evaluasi fasilitas RPH X adalah 199 yang berarti bahwa fasilitas RPH X termasuk kategori kurang sesuai dengan persyaratan.

\section{Pengelolaan Air Limbah RPH X}

Secara umum, air limbah RPH X terdiri atas urin, darah, lemak, dan air bekas pencucian. Secara lebih lengkap, air limbah RPH X terdiri atas urin dan air bekas pencucian kandang yang dihasilkan dari proses penerimaan dan penampungan; air bekas pencucian ruang, peralatan, dan hewan yang dihasilkan dari proses persiapan penyembelihan; darah dan air bekas pencucian yang dihasilkan dari proses penyembelihan; lemak yang tidak dapat dimakan yang dihasilkan dari proses pengulitan; darah dan air bekas pencucian jeroan yang dihasilkan dari proses pengeluaran jeroan; serta darah dan air bekas pencucian yang dihasilkan dari proses pembelahan karkas seperti yang diperlihatkan pada Gambar 1. Semua air limbah tersebut kemudian dialirkan melalui saluran dari kandang penampungan dan bangunan utama RPH $\mathrm{X}$ ke kolam penampungan untuk diolah lebih lanjut dengan IPAL. Namun, pengelola RPH X belum melakukan minimisasi air limbah sehingga dapat meningkatkan beban pengolahan air limbah di IPAL. Pengoperasian IPAL dilakukan oleh satu Kepala Koordinator Kebersihan dan Pengolahan Limbah dan tiga operator. Teknologi IPAL yang digunakan di RPH X adalah lamella clarifier. Pada lamella clarifier tank terjadi proses pemisahan secara fisik antara lumpur dan air hasil pengolahan. Lamella di RPH X dapat dilihat pada Gambar 2.

Secara umum, proses pengolahan air limbah RPH X terdiri atas ekualisasi, netralisasi, koagulasi, flokulasi, lamella clarifying, aerasi, pengendapan, anoxic treatment, klorinasi, penampungan, pengukuran, dan pengaliran ke Sungai Cisadane.
Diagram alir pengolahan air limbah RPH X dapat dilihat pada Gambar 3.

\section{Kualitas Air Limbah RPH X}

Data kualitas air limbah RPH X diperoleh dari data primer melalui uji laboraotorium dan data sekunder melalui laporan RPH X. Data primer berupa data kualitas air limbah pada inlet dan outlet IPAL, sedangkan data sekunder berupa data kualitas air limbah pada outlet IPAL. Parameter kualitas air limbah RPH X yang diukur mengacu pada Peraturan Menteri Lingkungan Hidup Republik Indonesia No. 5 tahun 2014 (Lampiran XLV) yang terdiri atas parameter fisika (TSS) dan parameter kimia (BOD, COD, minyak dan lemak, amonia, $\mathrm{pH}$ ), serta dilakukan juga pengukuran parameter mikrobiologi (bakteri fecal). Hasil pengukuran kualitas air limbah RPH X pada outlet IPAL dari tahun 2013 hingga 2017 dapat dilihat pada Tabel 4.

Peneliti juga melakukan pengukuran kualitaa air limbah RPH X pada in;et dan outlet IPAL yang dapat dilihat pada Tabel 5.

\section{Status Mutu Air}

Hasil pengukuran kualitas air limbah RPH X pada outlet IPAL kemudian dianalisis dengan uji Storet untuk menentukan status mutu air. Uji Storet dilakukan pada parameter fisika (TSS) dan parameter kimia (BOD, COD, minyak dan lemak, amonia, $\mathrm{pH}$ ) untuk dibandingkan dengan baku mutunya. Hasil uji Storet pada air limbah outlet IPAL dapat dilihat pada Tabel 6.

Berdasarkan Tabel 6. dapat dilihat bahwa status mutu air pada outlet IPAL termasuk ke dalam kategori Kelas A yang berarti bahwa kualitas air outlet IPAL baik sekali atau telah memenuhi baku mutu.

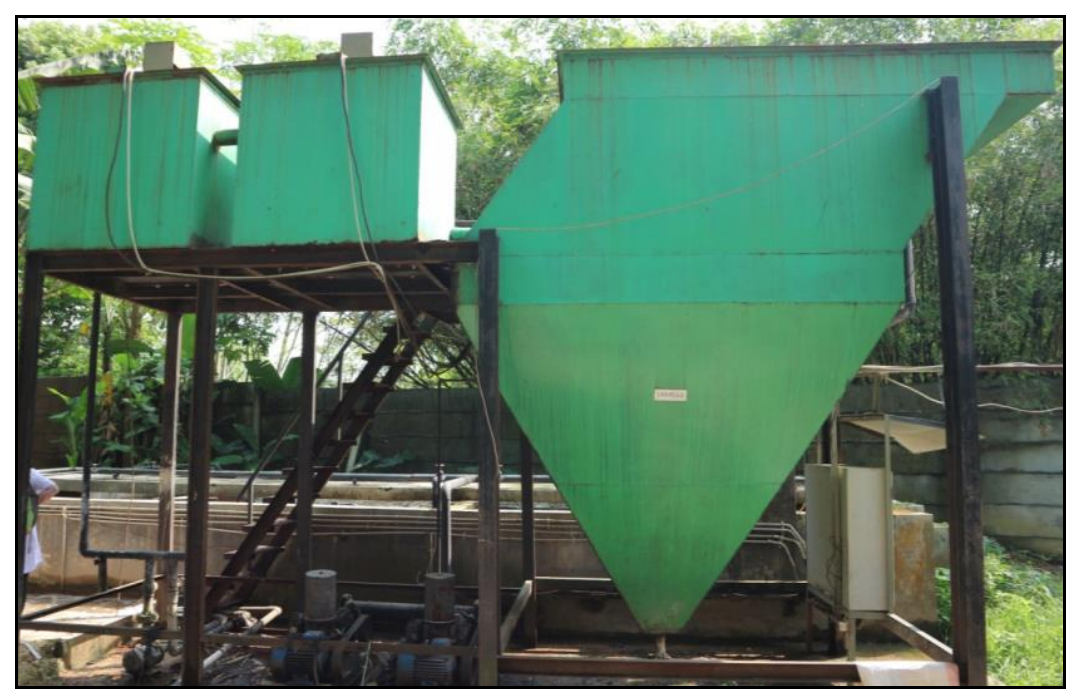

Gambar 2. Lamella di RPH X (Dokumentasi: Hasil observasi, 2017). 


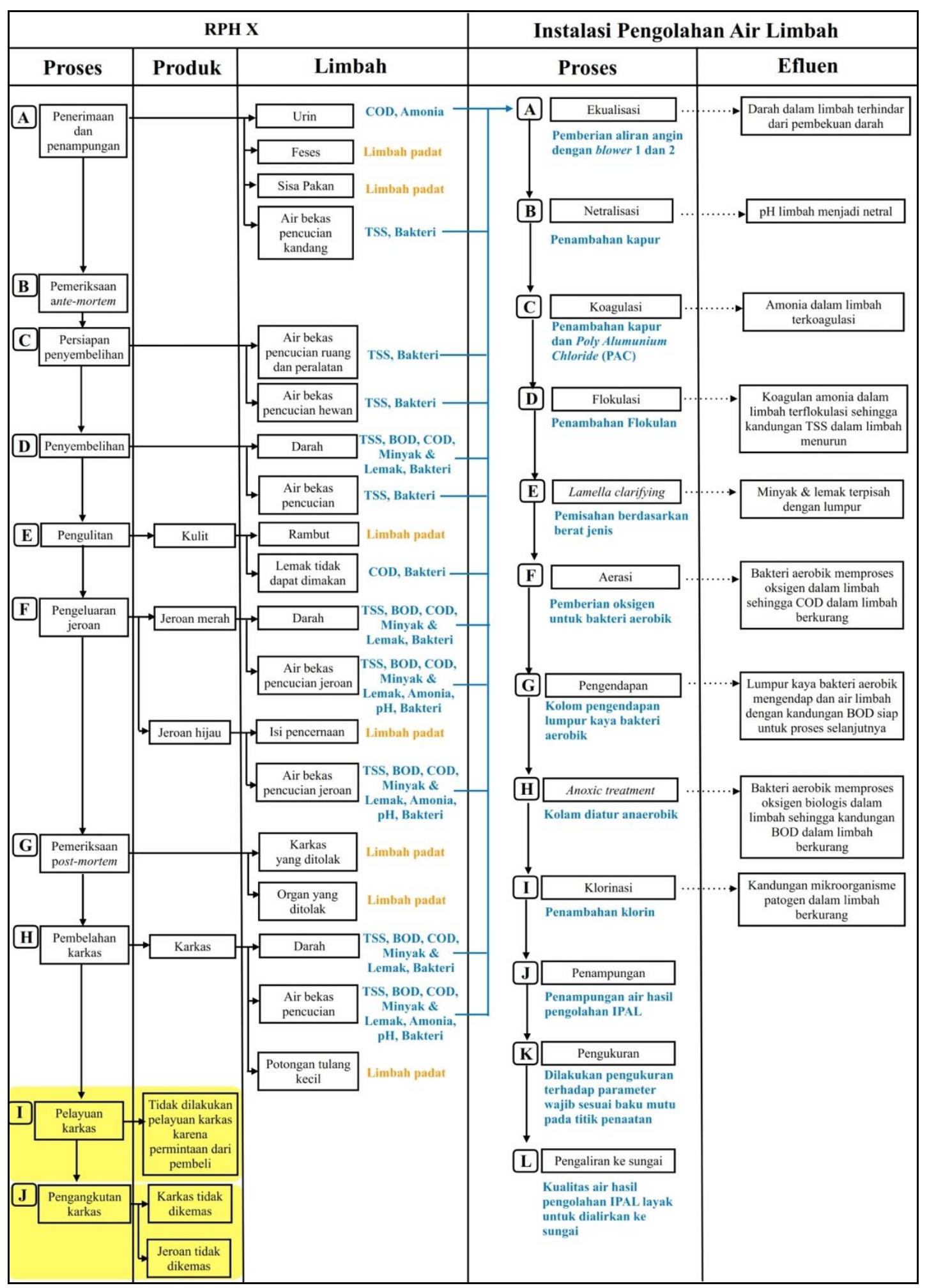

Gambar 3. Diagram alir pengolahan air limbah RPH X (Sumber: Hasil olah data primer, 2017).

Dampak Limbah RPH X pada Masyarakat yang Bertempat Tinggal di Sekitar RPH X

Responden pada riset ini adalah masyarakat RW 2 Kelurahan Bubulak Kecamatan Bogor Barat. Responden ini dipilih karena bertempat tinggal paling dekat dengan RPH X. Selain itu, pemilihan responden juga mengacu pada arah angin terbanyak pada bulan Januari-Oktober 2017 yaitu Utara. Oleh karena itu, masyarakat RW 2 Kelurahan Bubulak
Kecamatan Bogor Barat dipilih sebagai responden karena paling berdampak pada gangguan yang dihasilkan oleh kegiatan RPH X. Penyebaran kuesioner dilakukan pada hari kerja dengan tujuan untuk mendapatkan sampel yang dapat memberikan informasi terkait kondisi sehari-hari dari wilayah riset. Data kuesioner kemudian ditabulasi yang dapat dilihat pada Tabel 7. 
Tabel 4. Hasil pengukuran kualitas air limbah RPH X pada outlet IPAL.

\begin{tabular}{|c|c|c|c|c|c|c|c|c|c|c|}
\hline \multirow{2}{*}{ No. } & \multirow{2}{*}{ Parameter } & \multirow{2}{*}{ Satuan } & Baku & \multicolumn{7}{|c|}{ Tahun } \\
\hline & & & Mutu & \multicolumn{2}{|c|}{2013} & 2014 & \multicolumn{2}{|c|}{2016} & \multicolumn{2}{|c|}{2017} \\
\hline 1 & TSS & $\mathrm{mg} / \mathrm{L}$ & 100 & 9 & 9 & 8 & 2 & 11 & 11 & 18 \\
\hline & Kimia & & & & & & & & & \\
\hline 2 & BOD & $\mathrm{mg} / \mathrm{L}$ & 100 & 30 & 3,5 & 30 & 6,7 & 8,6 & 6,4 & 6 \\
\hline 3 & COD & $\mathrm{mg} / \mathrm{L}$ & 200 & 75 & 52,64 & 39,55 & 37,58 & 61,32 & 46,72 & 21 \\
\hline 4 & Minyak dan Lemak & $\mathrm{mg} / \mathrm{L}$ & 15 & 1,8 & $<1$ & 1,6 & 4,6 & $<1$ & 12 & $<1,4$ \\
\hline 5 & Amonia $\left(\mathrm{NH}_{3}-\mathrm{N}\right)$ & $\mathrm{mg} / \mathrm{L}$ & 25 & - & - & - & 0,792 & 5,306 & 0,808 & 1,06 \\
\hline 6 & $\mathrm{pH}$ & - & $6,0-9,0$ & 7,93 & 8,21 & 6,92 & 6,88 & 8,15 & 7,38 & 7,99 \\
\hline & Mikrobiologi & & & & & & & & & \\
\hline 7 & Bakteri fecal & $\begin{array}{l}\text { Jumlah/ } \\
100 \mathrm{~mL}\end{array}$ & - & & 100 & 70 & 600 & 92000 & 20 & 28 \\
\hline
\end{tabular}

Tabel 5. Hasil pengukuran kualitas air limbah RPH X pada inlet dan outlet IPAL.

\begin{tabular}{llcccc}
\hline \multirow{2}{*}{ No. } & Parameter & \multirow{2}{*}{ Satuan } & \multirow{2}{*}{ Baku Mutu } & \multicolumn{2}{c}{ Air limbah IPAL } \\
\cline { 5 - 6 } 1 & & & & Inlet & Outlet \\
\hline & Fisika & mg $/ \mathrm{L}$ & 100 & 48 & 22 \\
\hline & Kimia & & & & \\
2 & BOD & & 100 & 169 & 32 \\
3 & $\mathrm{COD}$ & $\mathrm{mg} / \mathrm{L}$ & 200 & 400 & 101 \\
4 & Minyak dan lemak & $\mathrm{mg} / \mathrm{L}$ & 15 & $<0,9$ & $<0,9$ \\
5 & Amonia $\left(\mathrm{NH}_{3}-\mathrm{N}\right)$ & $\mathrm{mg} / \mathrm{L}$ & 25 & 122,3 & 1,75 \\
6 & $\mathrm{pH}$ & - & $6,0-9,0$ & 7,4 & 8,1 \\
\hline & Mikrobiologi & Jumlah/100 $\mathrm{mL}$ & - & 3100 & 300 \\
\hline
\end{tabular}

Tabel 6. Hasil uji Storet pada air limbah outlet IPAL.

\begin{tabular}{|c|c|c|c|c|c|}
\hline \multicolumn{3}{|c|}{ Parameter } & Nilai & Baku Mutu & Skor \\
\hline \multirow{3}{*}{ Fisika } & \multirow{3}{*}{ TSS } & Maksimum & 22 & \multirow{3}{*}{100} & 0 \\
\hline & & Minimum & 2 & & 0 \\
\hline & & Rata-rata & 12,8 & & 0 \\
\hline \multirow{15}{*}{ Kimia } & \multirow{3}{*}{ BOD } & Maksimum & 32 & \multirow{3}{*}{100} & 0 \\
\hline & & Minimum & 6 & & 0 \\
\hline & & Rata-rata & 19 & & 0 \\
\hline & \multirow{3}{*}{ COD } & Maksimum & 101 & \multirow{3}{*}{200} & 0 \\
\hline & & Minimum & 21 & & 0 \\
\hline & & Rata-rata & 61 & & 0 \\
\hline & \multirow{3}{*}{$\begin{array}{l}\text { Minyak dan } \\
\text { Lemak }\end{array}$} & Maksimum & 12 & \multirow{3}{*}{15} & 0 \\
\hline & & Minimum & 0,9 & & 0 \\
\hline & & Rata-rata & 3,83 & & 0 \\
\hline & \multirow{3}{*}{$\begin{array}{l}\text { Amonia } \\
\left(\mathrm{NH}_{3}-\mathrm{N}\right)\end{array}$} & Maksimum & 5,306 & \multirow{3}{*}{25} & 0 \\
\hline & & Minimum & 0,792 & & 0 \\
\hline & & Rata-rata & 1,943 & & 0 \\
\hline & \multirow{3}{*}{$\mathrm{pH}$} & Maksimum & 8,15 & \multirow{3}{*}{$6-9$} & 0 \\
\hline & & Minimum & 6,88 & & 0 \\
\hline & & Rata-rata & 7,70 & & 0 \\
\hline Kategori & Kelas A & Baik Sekali & $\begin{array}{l}\text { Memenuhi } \\
\text { Baku Mutu }\end{array}$ & Skor Total & 0 \\
\hline
\end{tabular}

Sumber: hasil olah data sekunder, 2017

Tabel 7 menunjukkan bahwa sebanyak 100\% responden merasa keberadaan RPH X menimbulkan gangguan bau. Gangguan bau ini dirasakan responden sepanjang hari mulai dari pagi hingga malam hari. Gangguan bau terparah dirasakan responden ketika suhu udara semakin tinggi yaitu bulan Mei-Juni 2017. Gangguan bau ini berasal dari limbah padat RPH X yang ditumpuk di area terbuka. Penumpukan limbah padat di area terbuka ini disebabkan oleh tidak berfungsinya 
Tabel 7. Dampak limbah RPH X

\begin{tabular}{|c|c|c|c|}
\hline No. & Parameter & Jumlah responden & Persentase \\
\hline 1 & $\begin{array}{l}\text { Responden menggunakan jasa pemotongan } \\
\text { sapi di RPH X. }\end{array}$ & 0 & $0 \%$ \\
\hline 2 & $\begin{array}{l}\text { Responden merasa keberadaan RPH X } \\
\text { menimbulkan gangguan bau. }\end{array}$ & 39 & $100 \%$ \\
\hline 3 & $\begin{array}{l}\text { Responden merasa keberadaan RPH X } \\
\text { menimbulkan gangguan kesahatan. }\end{array}$ & 16 & $41 \%$ \\
\hline 4 & $\begin{array}{l}\text { Responden merasa keberadaan RPH X } \\
\text { menimbulkan gangguan suara. }\end{array}$ & 5 & $13 \%$ \\
\hline \multirow[t]{5}{*}{5} & $\begin{array}{l}\text { Sumber air yang responden gunakan sehari- } \\
\text { hari: }\end{array}$ & & \\
\hline & a. Sumur & 21 & $54 \%$ \\
\hline & b. PDAM & 18 & $46 \%$ \\
\hline & c. Sungai Cisadane & 0 & $0 \%$ \\
\hline & Total & 39 & $100 \%$ \\
\hline 6 & $\begin{array}{l}\text { Menurut responden, air limbah yang } \\
\text { dihasilkan dari } \mathrm{RPH} X \text { dapat mencemari } \\
\text { sumber air yang digunakan sehari-hari. }\end{array}$ & 14 & $36 \%$ \\
\hline 7 & $\begin{array}{l}\text { Responden telah berpartisipasi } \\
\text { menyumbangkan dana dan/atau tenaga } \\
\text { dalam pengelolaan limbah di RPH X. }\end{array}$ & 16 & $41 \%$ \\
\hline 8 & $\begin{array}{l}\text { Responden bersedia untuk berpartisipasi } \\
\text { menyumbangkan dana dan/atau tenaga } \\
\text { dalam pengelolaan limbah di RPH X. }\end{array}$ & 23 & $59 \%$ \\
\hline \multirow[t]{6}{*}{9} & $\begin{array}{l}\text { Menurut responden yang bertanggungjawab } \\
\text { dalam pengelolaan limbah di RPH X yaitu: }\end{array}$ & & \\
\hline & a. Pengelola RPH X & 35 & $90 \%$ \\
\hline & b. Pemerintah terkait & 2 & $5 \%$ \\
\hline & c. Masyarakat yang tinggal di sekitar RPH X & 0 & $0 \%$ \\
\hline & d. Seluruh pihak $(a, b$, dan $c)$ & 2 & $5 \%$ \\
\hline & Total & 39 & $100 \%$ \\
\hline
\end{tabular}

sistem pengelolaan limbah padat di RPH X. Hal ini dikarenakan pupuk hasil olahan limbah padat RPH $\mathrm{X}$ tidak dapat bersaing di pasaran. Gangguan bau yang berasal dari limbah padat RPH ini paling sering dirasakan responden ketika siang hari. Selain itu, gangguan bau juga berasal dari limbah cair RPH X khususnya bau amis darah sapi. Gangguan bau yang berasal dari limbah cair RPH ini paling sering dirasakan responden ketika malam hingga pagi hari. Hal ini dikarenakan proses pemotongan sapi di RPH X dimulai pukul 21.00 WIB hingga 05.00 WIB. Darah sapi beserta air limbah RPH X lainnya dialirkan melalui saluran air limbah di bangunan utama menuju kolam penampungan untuk diproses dengan IPAL selanjutnya. Hasil ini senada dengan riset sebelumnya yang dilakukan oleh Lestari (2015) yang menyatakan bahwa sebanyak $74,18 \%$ responden merasa terganggu dengan bau limbah RPH.

Tabel 7. menunjukkan bahwa sebanyak $41 \%$ responden merasa keberadaan RPH X menimbulkan gangguan kesahatan. Gangguan kesehatan yang dirasakan responden yaitu rasa mual akibat bau yang berasal dari limbah RPH X.
Hal ini disebabkan pembusukan limbah RPH menghasilkan gas amonia $\left(\mathrm{NH}_{3}\right)$ dan hidrogen sulfida $\left(\mathrm{H}_{2} \mathrm{~S}\right)$. Gas $\mathrm{NH}_{3}$ dan $\mathrm{H}_{2} \mathrm{~S}$ tersebut menimbulkan bau busuk yang dapat menyebabkan gangguan pada saluran pernapasan yang disertai dengan reaksi tubuh berupa rasa mual dan kehilangan selera makan.

Berdasarkan hasil kuesioner, mayoritas responden tidak merasa terganggu dengan suara yang ditimbulkan oleh kegiatan di RPH X. Hal ini dikarenakan proses pemotongan sapi di RPH X tidak menggunakan mesin sehingga tidak menimbulkan suara yang bising. Hanya 13\% responden yang merasa keberadaan RPH X menimbulkan gangguan suara. Gangguan suara yang dirasakan responden tersebut terjadi ketika malam hingga pagi hari. Gangguan suara ini berasal dari lalu lintas kendaraan angkut karkas dan suara tembakan dari stunning gun ketika proses pemingsanan sapi berlangsung. Hasil ini senada dengan riset sebelumnya yang dilakukan oleh Lestari (2015) yang menyatakan bahwa hanya $22,53 \%$ responden yang merasa terganggu dengan suara yang ditimbulkan dari RPH. 
Berdasarkan hasil kuesioner, sebanyak 54\% responden menggunakan sumur bor sebagai sumber air, diikuti $46 \%$ responden yang menggunakan PDAM sebagai sumber air, dan tidak terdapat responden yang menggunakan Sungai Cisadane sebagai sumber air untuk digunakan sehari-hari. Hasil wawancara responden menunjukkan bahwa sebelum RPH X beroperasi, air Sungai Cisadane masih digunakan responden untuk mencuci pakaian dan mandi. Namun, semenjak RPH X beroperasi khususnya ketika Hari Raya Idul Adha, air Sungai Cisadane tidak dapat digunakan karena telah tercampur oleh darah yang dihasilkan dari pemotongan hewan kurban di RPH X. Pada saat Hari Raya Idul Adha, jumlah sapi yang dipotong di RPH X melebihi kapasitas pemotongan sapi yaitu mencapai 100 sapi/hari selama tiga hari berturutturut. Hal ini menyebabkan darah yang dihasilkan dari pemotongan hewan kurban di RPH X langsung dialirkan ke Sungai Cisadane. Selain itu, penumpukan limbah padat RPH X di area terbuka yang berlokasi di dekat Sungai Cisadane menyebabkan air limpasan limbah padat tersebut dapat langsung mengalir ke sungai ketika hujan. Selain itu, hasil kuesioner menunjukkan bahwa menurut mayoritas responden, air limbah yang dihasilkan dari RPH X tidak mencemari sumber air yang digunakan sehari-hari. Hal ini dikarenakan sumber air yang digunakan responden berasal dari sumur bor dengan kedalaman sumur mencapai 12 meter dan PDAM.

Berdasarkan hasil kuesioner, sebanyak $41 \%$ responden telah berpartisipasi baik menyumbangkan dana maupun tenaga dalam pengelolaan limbah di RPH X. Partisipasi yang dilakukan responden berupa penanaman bambu kersik di sekitar halaman masyarakat yang berbatasan dengan RPH X guna mengurangi bau limbah yang dihasilkan dari RPH X. Selanjutnya, berdasarkan hasil kuesioner sebanyak 59\% responden bersedia untuk berpartisipasi baik menyumbangkan dana maupun tenaga dalam pengelolaan limbah di RPH X. Hasil wawancara menunjukkan bahwa responden bersedia bekerjasama dengan pengelola RPH X untuk mengurangi gangguan bau.

Berdasarkan hasil kuesioner, menurut responden yang bertanggungjawab dalam pengelolaan limbah di RPH X adalah pengelola RPH sebesar $90 \%$, diikuti pemerintah terkait sebesar 5\%, seluruh pihak sebesar 5\%, dan masyarakat yang tinggal di sekitar RPH X sebesar $0 \%$. Responden berharap mendapatkan ganti rugi dari pengelola RPH X atas gangguan bau yang diterimanya. Responden juga meminta pengelola $\mathrm{RPH} \mathrm{X}$ untuk melakukan penyemprotan secara rutin guna mengurangi bau. Selain itu, responden juga berharap agar pengelolaan limbah RPH X dapat berjalan lebih baik.

\section{KESIMPULAN}

Berdasarkan hasil dan pembahasan, maka kesimpulan dari riset ini adalah praktik pemotongan sapi di RPH X termasuk kategori baik. Praktik pemotongan sapi di RPH X yang belum sesuai prosedur yaitu parameter penerimaan dan penampungan; persiapan penyembelihan; penyembelihan; pengulitan; pelayuan karkas; dan pengangkutan karkas. Fasilitas RPH X termasuk kategori kurang sesuai dengan persyaratan yang ditetapkan oleh Menteri Pertanian. Fasilitas RPH X yang belum memenuhi persyaratan yaitu parameter: lokasi; sarana/prasarana pendukung; bangunan utama; area penurunan hewan; kandang penampung dan istirahat hewan; kandang penampung ruminansia betina produktif; kandang isolasi; area pemuatan karkas dan/atau daging; kantor administrasi dan kantor dokter hewan; kantin dan mushola; ruang istirahat karyawan dan tempat penyimpanan barang pribadi/ruang ganti pakaian; kamar mandi dan WC; fasilitas pemusnahan bangkai atau insinerator; sarana penanganan limbah; rumah jaga; peralatan; dan higiene dan sanitasi.

Pengelolaan air limbah RPH X belum optimal. Hal ini dikarenakan pengelola RPH X belum melakukan minimasi pada air limbah RPH X sehingga meningkatkan beban pengolahan air limbah di IPAL. Kualitas air limbah RPH X pada inlet IPAL berada di atas nilai baku mutu air limbah bagi kegiatan RPH. Setelah dilakukan pengolahan dengan IPAL, kualitas air limbah RPH X pada outlet IPAL berada di bawah nilai baku mutu air limbah bagi kegiatan RPH. Hasil uji Storet menunjukkan bahwa status mutu air pada outlet IPAL termasuk kategori kelas A yang berarti bahwa kualitas air outlet IPAL baik sekali atau telah memenuhi baku mutu. Dampak limbah RPH X pada masyarakat yang bertempat tinggal di sekitar RPH X yaitu gangguan bau yang dirasakan oleh $100 \%$ responden dan gangguan kesehatan yang dirasakan oleh $41 \%$ responden. Gangguan kesehatan tersebut berupa rasa mual yang disebabkan oleh bau dari limbah RPH X.

\section{DAFTAR PUSTAKA}

Akan, J., and Mohmoud, S., 2010. Bioaccumulation of Some Heavy Metals in Fish Samples from River Benue in Vinikilang, Adamawa State, Nigeria. Amer. J. Environment, 3(11):727-736. 
Akinro, A., Ologunabga, I., and Yahaya, O., 2009. Environmental Implications of Unhygienic Operation of a City Abattoir in Akure, Western Nigeria. J. Engineering \& Applied Sciences, 4(9):60-63.

Badan Pusat Statistik (BPS) Provinsi Jawa Barat, 2015. Statistik Pemotongan Ternak Provinsi Jawa Barat Tahun 2015. Bandung: BPS Provinsi Jawa Barat.

Bello, W., 2009. Problems and Prospect of Organic Farming in Developing Countries. Ethiopian Journal of Environmental Studies and Management, 1(1):36-43.

Budiyono, Widiasa, I.N., Johari, S., dan Sunarso, 2011. Study on Slaughterhouse Wastes Potency and Characteristic for Biogas Production. Internat. J. Waste Resources, 1(2):4-7.

Codex Alimentarius Commission (CAC). (2004). Join FAO/WHO Food Standard Programe. Report of the Tenth Session of the Codex Committee on Meat Hygiene. Geneva (CH): Codex Alimentarius Commission.

Iskandar, F., 2014. Kajian Dampak Kegiatan Rumah Potong Hewan Terpadu Bubulak Kota Bogor terhadap Mutu Air Sungai Cisadane.
Tesis. Bogor: Fakultas Kedokteran Hewan Institut Pertanian Bogor.

Lestari, A., 2015. Evaluasi Pemotongan dan Persepsi Masyarakat Terhadap Limbah pada Tempat Pemotongan Hewan (TPH) Kuda di Kabupaten Jeneponto. Tesis. Bogor: Institut Pertanian Bogor.

Padmono, D., 2005. Alternatif Pengolahan Limbah Rumah Potong Hewan-Cakung (Suatu Studi Kasus). Jurnal Teknologi Lingkungan, 6(1):303-310.

Singh, S., Vijayanand, S., and Moholkar, M., 2014. Optimization of Carboxymethylcellulase Production from Bacillus amyloliquefaciens SS35. Biotech, 4(4):411-424.

Tawaf, R., Rachmawan O, dan Firmansyah C., 2013. Pemotongan Sapi Betina Umur Produktif dan Kondisi RPH di Pulau Jawa dan Nusa Tenggara. Workshop Nasional Konservasi dan Pengembangan Sapi Lokal. Fakultas Peternakan Unpad. Bandung.

Widya, N., Burdiarsa, W., dan Mahendra, M.S., 2008. Studi Pengaruh Air Limbah Pemotongan Hewan dan Unggas terhadap Kualitas Air Sungai Subak Pakel I di Desa Darmasaba Kecamatan Abiansemal Kabupaten Badung. Ecotrophic, 3(2):55-60. 